\author{
Oscar Mejía Quintana \\ Universidad Nacional, Colombia \\ omejiaq@unal.edu.co
}

\title{
Del liberalismo racional al republicanismo razonable
}

\begin{abstract}
Resumen
In the 1980s Rawls incorporated a series of reformulations to his initial postulates of the Theory of Justice. On the one hand, he subsumes communitarian criticism, and on the other hand, he incorporates a late influence of both Republican tradition and Hegelian philosophy to his conceptual corpus. One of the key aspects of his reformulation is that he distances himself from a theoretical procedural rational model and begins to emphasize the political terms of practical reasonability in Political Liberalism. The purpose of this article is to illustrate the theoretical mediation that the notion of deliberative democracy provides for these effects.
\end{abstract}

Key Words: Rawls, Hegel, Liberalism, Republicanism, Rational, Reasonable, Deliberative democracy.

\section{Introducción}

El pensamiento de Rawls constituye para muchos el resurgimiento de la filosofía política en la segunda mitad del siglo XX. Se origina, cronológicamente, con la publicación de la Teoría de la Justicia (1971) de John Rawls, cuyos trazados establecen un audaz intento por fundamentar una nueva concepción de la moral, la política y el derecho, y de sus relaciones entre sí, con sustanciales connotaciones para el desarrollo institucional de la democracia e inaugurando con ello un proyecto alternativo. La Teoría de la Justicia termina de redondear la crítica al utilitarismo que Rawls había emprendido 20 años atrás, cuando decide acoger la tradición contractualista como la más adecuada para concebir una concepción de justicia como equidad capaz de satisfacer por consenso las expectativas de igual libertad y justicia distributiva de la sociedad. Para ello concibe un procedimiento de consensualización, la posición original, del que se derivan, en condiciones simétricas de libertad e igualdad argumentativas, unos principios de justicia que 
orientan la construcción institucional de la estructura básica de la sociedad, a nivel político, económico y social (Rawls, 1979).

El diseño rawlsiano genera un debate sin precedentes en el campo de la filosofía política que, aunque se inicia en los Estados Unidos, se extiende rápidamente a Europa y otras latitudes por sus implicaciones para la crítica y reestructuración institucional de la democracia liberal decimonónica, en el marco tanto de una severa crisis de legitimidad como de una tendencia globalizadora, de carácter neoconservador -en nuestras latitudes, neoliberal,l que exige radicales reformas internas a la misma.

Las primeras reacciones a la propuesta rawlsiana, en la misma década del 70, van a provenir, desde la orilla liberal, de los modelos neocontractualistas de Nozick (1988) y Buchanan (1975), siguiendo a Hobbes y Locke respectivamente, y más tarde, aunque en forma menos sistemática, la del mismo Hayek (1995). Un tanto tardía, diez años después, Gauthier (1994) igualmente se inscribe en el marco de esta crítica neoliberal a Rawls. Todas teniendo como denominador común la reivindicación de la libertad sin constricciones, la autorregulación de la economía sin intervencionismo estatal, la minimización del Estado y la reivindicación del individuo y su racionalidad instrumental.

Iniciando la década de los 80 ' se origina la reacción comunitarista de MacIntyre (1981), Taylor (1989), Walzer (1983) y Sandel (1982) que da origen a una de las más interesantes polémicas filosófico-políticas del siglo XX (Mulhall \& Swift) quienes configuran una especie de versión contemporánea de los "Jinetes del Apocalipsis" por lo radical de la misma y la sustancial confrontación que le plantean a todo el proyecto (neo)liberal de la modernidad.

Dworkin (1996), con su propuesta de una comunidad liberal y la necesidad de que el liberalismo adopte una ética de la igualdad, fundamenta la posibilidad de que, coexistiendo con sus principios universales de tolerancia, autonomía del individuo y neutralidad del Estado, el liberalismo integre valores reivindicados por los comunitaristas como necesarios para la cohesión de la sociedad, tales como la solidaridad y la integración social, en un nuevo tipo de "liberalismo integrado o sensible a la comunidad" (Ferrara, 1994 : 122).

Will Kymlicka (1995) tercia en toda esta discusión intentando crear una teoría liberal sensible a los supuestos comunitaristas que equilibre tanto los derechos humanos, irrenunciables para la tradición liberal, como los derechos diferenciados en función de grupo, aquellos que permitirían la satisfacción de las exigencias y reivindicaciones de las minorías culturales que no pueden abordarse exclusivamente a partir de las categorías derivadas de los derechos individuales.

La discusión se revigoriza con la publicación del libro de Rawls, Political Liberalism, en sus dos ediciones de 1993 y 1997 (Rawls, 1996) donde es innegable la influencia determinante tanto del arsenal comunitarista (y su lectura de Hegel) como de la tradición republicana, forzando una revisión de los principios 
liberales decimonónicos y dando origen a un nuevo tipo de liberalismo político que pocos se atreverían a identificar con su antecesor.

El escrito pretende ilustrar, como hipótesis de trabajo, que

A partir de los ochenta Rawls introduce una serie de reformulaciones en su planteamiento inicial, subsumiendo, de una parte, las críticas comunitaristas y, de otra, incorporando a su corpus conceptual la influencia tardía tanto de la tradición republicana como de la filosofía hegeliana, siendo uno de los puntos neurálgicos de este replanteamiento la distancia que toma del modelo racional teórico de Teoría de la Justicia y el acento que empieza a colocar en los términos de razonabilidad práctica en Liberalismo Político, gracias a las categorías de overlapping consensus y razón pública que, en últimas, le permiten concretar un modelo de democracia deliberativa enraizado tanto en el republicanismo político anglosajón como en la filosofía del derecho de Hegel.

En orden a ilustrar esta hipótesis, el texto realiza en primer lugar un repaso de la Teoría de la Justicia, donde se quiere dejar en claro los constructos que inspiran este liberalismo racional inicialmente y en qué sentido las figuras de la desobediencia civil y del equilibrio reflexivo constituyen ya un tránsito al énfasis en la razonabilidad que se asumirá posteriormente, en el escrito sobre constructivismo kantiano en teoría moral donde Rawls da un giro hacia el comunitarismo, asumiendo sus criticas y tratando de darles solución a través de la categoría de persona moral.

Posteriormente se abordará tanto la tradición republicana como el hegelianismo con el objetivo, primero, de definir las diferentes tendencias de aquel, básicamente lo que podríamos denominar neo-republicanismo de origen y evolución anglosajona, representada por autores como Pocock y Skinner, y post-republicanismo, que se desarrolla en Francia y que tiene como representantes a una nueva generación de autores, dentro de los que se destacan Luc Ferry, Alain Renaut y Sylvie Messure. Y segundo, introducir, igualmente, las principales categorías de la filosofía hegeliana con el fin de precisar las fuentes que serán clave en la comprensión del último Rawls.

La tercera parte estará dedicada a la recepción que tanto el republicanismo como el hegelianismo tienen en el último y los cambios que Rawls realiza en su obra tardía. Se aborda aquí las últimas lecciones de filosofía moral que Rawls da en Harvard y que versan concretamente sobre la filosofía del derecho de Hegel de la cual retomará ideas fundamentales para su desarrollo posterior. Enseguida, se revisarán los cambios hechos por Rawls en Liberalismo Político, destacando la propuesta de un consenso entrecruzado y sus diferentes momentos donde queda en evidencia la recepción del republicanismo anglosajón. Y, de igual manera, 
las reformulaciones posteriores tanto en Una revisión de la idea de razón pública, su último texto, como en Justicia como Equidad: una Reformulación, donde la influencia del hegelianismo parece ser inobjetable .

\section{La Teoría de la Justicia}

\section{El liberalismo racional}

La crisis de legitimidad de la sociedad contemporánea pretenderá ser superada por John Rawls a través de unos principios de justicia consensualmente concertados que permitan orientar y corregir el ordenamiento jurídico-político desde unos criterios que puedan satisfacer las expectativas, diferencias y desigualdades de la pluralidad de sujetos colectivos que conforman la ciudadanía. El paradigma del derecho que se deduce de esta concepción política de la justicia plantea un procedimiento consensual de construcción jurídica (Martinez, 1992; Nino, 1989; Da Silveira et al., 1996) en la concepción, concreción y ejecución de contenidos, instrumentos y productos jurídico-legales de todo orden (Mejía, 1996; 1997).

Desde la Teoría de la Justicia Rawls (1978) ha concebido este procedimiento de argumentación consensual como el instrumento para garantizar que los principios de justicia social o cualquier tipo de principios normativo-procedimentales que deban orientar la sociedad sean escogidos dialogicamente, rodeando el proceso de las condiciones necesarias para que no sea contaminado por intereses particulares y se garantice la universalidad y validez normativa de los mismos.

El constructo metodológico que utiliza para ello es el de la posición original, con el cual se pretende describir un estado hipotético inicial que asegure la 174 neutralidad de los principios y la simetría discursiva y, como consecuencia de ello, la imparcialidad en su interior (Rawls, 1978). El velo de ignorancia, principal mecanismo metodológico, tendrá el propósito de representar la potencial discusión simétrica pública sobre la estructura básica de la sociedad, asegurando la libertad e igualdad argumentativas de los seres humanos y grupos sociales, con el fin de garantizar que la concepción pública de la justicia que se concerte sea el fruto de un procedimiento dialógico amplio y participativo.

La concepción de justicia pública que de ello se deriva no solo constituye el fundamento dialógico-moral, extra-sistémico, de todo el ordenamiento jurídico político sino que, simultáneamente, es un criterio de interpretación y legitimación de todas las medidas que el Estado tome en torno a la sociedad. De allí se desprenden tanto las interpretaciones constitucionales como las interpretaciones ciudadanas sobre cualesquiera leyes y medidas que afectan el orden social, tanto en su esfera pública como privada. 


\section{El tránsito a la razonabilidad}

Desobediencia civil como razonabilidad

En la Teoría de la justicia el concepto de desobediencia civil aparece como la parte final de las instituciones de la justicia, después de todo el proceso de fundamentación que Rawls había venido adelantando en los capítulos anteriores. De aquí puede deducirse que éste delimita su teoría de la desobediencia civil a un marco político específico (Malen, 1988; Estévez, 1994; Mejía, 2000). Efectivamente, para Rawls la desobediencia civil encuentra el ambiente propicio para su desarrollo en una sociedad casi justa, en su mayor parte bien ordenada y por consiguiente en una sociedad democrática que no está exenta de cometer injusticias contra una parte de sus integrantes.

Una vez establecido este marco, se puede entrar a estudiar la definición de desobediencia civil que aporta Rawls. Ésta se concibe como un "acto público, no violento, consciente y político, contrario a la ley, cometido habitualmente con el propósito de ocasionar un cambio en la ley o en los programas de gobierno" (Rawls, 1978 : 332). La desobediencia civil es un mecanismo de excepción con el que cuentan las minorías para defenderse de una mayoría que promulga leyes que están perjudicándolas y no quiere hacer caso a sus reclamos y exigencias. A través de la desobediencia civil se está apelando al sentido de justicia de la comunidad, argumentando la violación del acuerdo entre personas libres e iguales. Para Rawls también vale la pena tener en cuenta que "la desobediencia civil es un acto político, no sólo en el sentido en que va dirigido a la mayoría que ejerce el poder político, sino también porque es un acto guiado y justificado por principios políticos, es decir, por los principios de justicia que regulan la constitución y en general las instituciones sociales" (Rawls, 1978 : 333).

Dentro de la sociedad el manejo de la desobediencia civil resulta ser algo muy delicado, por lo cual Rawls coloca una serie de condiciones para su correcto ejercicio: en primer lugar, la desobediencia civil se aplica a casos claramente injustos como aquellos que suponen un óbice cuando se trata de evitar otras injusticias. Se trata de restringir la desobediencia a las violaciones de los dos principios de justicia rawlsianos y de manera más especifica a la violación del principio de libertad. Por otro lado, la desobediencia civil se concibe como el último recurso en ser utilizado, una vez han sido agotadas todas las vías legales debido a la falta de atención e indiferencia de las mayorías. Finalmente, la desobediencia civil debe darse dentro de un marco de absoluto respeto a la ley, porque ella "expresa la desobediencia a la ley dentro de los límites de la fidelidad a la ley, aunque está en el límite extremo de la misma". Con ella "se viola la ley, pero la fidelidad a la ley queda expresada por la naturaleza pública y no violenta del acto, por la voluntad de aceptar las consecuencias legales de la propia conducta" (Rawls, $1978: 334)$. 
Para Rawls esta última condición resulta ser muy importante pues permite probar a las mayorías que el acto del desobediente es político, sincero y legitimo, lo que apoya el llamado que se hace a la concepción de justicia de la comunidad. Para que la desobediencia civil dé resultados favorables Rawls también señala una serie de restricciones o precauciones que deben tener en cuenta los desobedientes: no se debe pretender colapsar o desestabilizar el sistema, se debe estar seguro de la imposibilidad de recurrir a los medios legales y se debe realizar un estudio concienzudo de la situación, para examinar la conveniencia del acto de desobediencia y, de ser necesario, recurrir a formas alternativas de protesta.

Pese a todo Rawls reconoce la posibilidad de una radicalización de la desobediencia civil, llegando a adquirir formas violentas, en caso de no ser debidamente atendidas las demandas de los desobedientes. Puesto que "quienes utilizan la desobediencia civil para protestar contra leyes injustas no están dispuestos a desistir de su protesta en caso de que los tribunales no estén de acuerdo con ellos" (Rawls, 1978 : 333) esta situación no deslegitima el acto de desobediencia. En este punto surge la pregunta por cuál es la última instancia posible para evaluar las razones y los actos de los desobedientes. El último tribunal de apelación, sostiene Rawls, es el electorado en general. No hay peligro de anarquía en tanto haya cierto acuerdo entre las concepciones de justicia que detentan los ciudadanos. Aunque la desobediencia civil está justificada, lo cierto es que parece amenazar la concordia ciudadana. En ese caso, la responsabilidad no recae en aquellos que protestan sino en aquellos cuyo abuso de poder y de autoridad justifica tal oposición porque usar el aparato coercitivo para mantener instituciones injustas es una forma de fuerza ilegítima a la que los hombres tienen derecho a resistirse.

Para concluir, vale la pena recordar que el adecuado uso de la desobediencia civil garantiza y fortalece la estabilidad del sistema político, pues por medio de ella se refuerzan las instituciones justas, permite rechazar las injusticias y corregir las divergencias y disputas. A través de medios como la desobediencia civil logran encontrar anclaje en la realidad las figuras y constructos de la democracia constitucional, que por momentos resultan ser excesivamente formales y teóricos.

\section{Radicalización de lo razonable}

Sin embargo, en el campo de la filosofía práctica existe un constructo aún más radical que la misma desobediencia civil, el equilibrio reflexivo, con la cual la plausibilidad de los principios se irá comprobando paulatinamente al contraponerlos con las propias convicciones y contrastarlos con orientaciones concretas en situaciones particulares (Schmidt, 1992). Esta figura admite dos lecturas, la primera es metodológica, y consiste en buscar argumentos convincentes que permitan aceptar como válidos el procedimiento y los principios derivados. En este momento se denomina equilibrio porque “... finalmente, 
nuestros principios y juicios coinciden; y es reflexivo puesto que sabemos a qué principios se ajustan nuestros juicios reflexivos y conocemos las premisas de su derivación" (Rawls, 1978 : 338). Este equilibrio no se concibe como algo estable o permanente, sino que se encuentra sujeto a transformaciones por exámenes ulteriores que pueden hacer variar la situación contractual inicial.

No basta justificar una determinada decisión racional; deben justificarse también los condicionantes y circunstancias procedimentales. En este sentido, se busca confrontar las ideas intuitivas sobre la justicia, que todos poseemos, con los principios asumidos, logrando un proceso de ajuste y reajuste continuo hasta alcanzar una perfecta concordancia. En este proceso tienen cabida tanto los juicios éticos como las concepciones morales de los individuos. Para esta lectura el equilibrio reflexivo se constituye en una especie de auditaje subjetivo desde el cual el individuo asume e interioriza los principios concertados como propios, pero con la posibilidad permanente de cuestionarlos y replantearlos de acuerdo a las nuevas circunstancias.

Ello se convierte en un recurso individual que garantiza que el ciudadano, en tanto persona moral, pueda tomar distancia frente a las decisiones mayoritarias que considere arbitrarias e inconvenientes; de esta manera, la "exigencia de unanimidad [...] deja de ser una coacción” (Rawls, 1978 : 623). La voluntad general no puede ser impuesta con el argumento de ser moralmente legítima por ser mayoritaria: tiene que ser subsumida libremente por el individuo, en todo tiempo y lugar. El equilibrio reflexivo es la polea que permite articular la dimensión política con la individual, dándole al ciudadano, como persona moral, la posibilidad de replantear los principios de justicia y la estructura social que se deriva de ellos cuando sus convicciones así se lo sugieran. De esta manera Rawls pretende resolver la contradicción que había quedado pendiente en el contractualismo clásico entre la voluntad general y la autonomía individual, que Kant había intentado resolver sin mucha fortuna.

La segunda lectura del equilibrio reflexivo es política y, sin duda, más prospectiva. Aquí, los principios deben ser refrendados por la cotidianidad misma de las comunidades en tres dimensiones contextuales específicas: la de la familia, la del trabajo y la de la comunidad, en general. Sólo cuando desde tales ámbitos los principios universales pueden ser subsumidos efectivamente, se completa el proceso. En este punto pueden darse varias alternativas: la primera es la aceptación de los principios, y del ordenamiento jurídico-político derivado de ellos, por su congruencia con nuestro sentido vital de justicia. La segunda es la marginación del pacto pero reconociendo que los demás sí pueden convivir con ellos y que es una minoría la que se aparta de sus parámetros, reclamando tanto el respeto para su decisión como las mismas garantías que cualquiera puede exigir dentro del ordenamiento. La tercera es el rechazo a los principios y la exigencia de recomenzar el contrato social, es decir, el reclamo por que el 
disenso radical sea tenido en cuenta para rectificar los términos iniciales del mismo. Normativamente significa que el pacto nunca se cierra y que siempre tiene que quedar abierta la posibilidad de replantearlo.

\section{Prioridad de lo razonable sobre lo racional}

Ante las múltiples críticas de liberales y comunitaristas, Rawls se permite corregir y llenar los vacíos que evidencian sus críticos. Aquí, específicamente se concentra en el aspecto moral de su planteamiento volviendo sobre la teoría kantiana, lo que sugiere la reasunción de elementos como la autonomía y el procedimiento de consensualización (Rubio, 1990). Sin ser propiamente kantiana pues, como algunos anotan, cuando más se reclama kantiano es cuando más claramente comienza a evidenciarse la toma de distancia frente a Kant; la revisión rawlsiana evidencia el precedente constructivista que infiere de la filosofía práctica kantiana (Camps, 1997).

El propósito de este apartado será explicar el constructivismo kantiano como el elemento que permite a Rawls asumir las críticas comunitaristas a su propuesta original, siendo este el punto en donde se muestra el giro que el autor hace hacia el comunitarismo. En esta etapa se da capital importancia al concepto de persona moral y a las facultades que esta posee, su sentido de justicia y su concepción de bien.

El constructivismo kantiano tiene un objetivo político fundamental: busca superar el conflicto que ha desgarrado a la democracia, fundamentando su solución a través de la persona moral del ciudadano. En tal sentido, articula el contenido de la justicia con una concepción de persona, en tanto libre e igual, capaz de actuar racional y razonablemente y, como tal, cooperar socialmente (Rubio, 1992).

El conflicto que ha dividido a la democracia ha sido el que se ha presentado entre dos tradiciones: la de la libertad, a partir de Locke, y la de la igualdad, a partir de Rousseau. La primera prioriza las libertades cívicas (pensamiento, conciencia, propiedad), y la segunda las libertades políticas, subordinando las primeras a estas últimas. El punto de superación de esta dicotomía puede encontrarse en una interpretación de la libertad y la igualdad congenial con la de persona moral. La justicia como equidad articula la concepción de persona moral con la de sociedad-bien-ordenada a través de un procedimiento de argumentación moral ilustrado en el modelo de la posición original. Con ello establece una mediación entre las dos, conectando la persona moral que elige los principios de justicia de una sociedad con el esquema de cooperación social de esa misma sociedad.

La autonomía plena se realiza en la vida diaria de los ciudadanos. Ella se define como racional, en cuanto la búsqueda del provecho personal de cada participante. Y aunque está incorporada a la estructura de la posición original, el 
criterio guía será siempre el que lo razonable subordina y presupone lo racional. Ello expresa un rasgo de unidad de la razón práctica: la razón práctica empírica está subordinada por la razón práctica pura. Esta unidad está garantizada porque lo razonable encuadra a lo racional, lo cual es una característica del constructivismo kantiano: la prioridad de lo justo sobre lo bueno.

Las personas morales poseen dos capacidades morales: la capacidad para un sentido de justicia efectivo (Bonete, 1990); y la capacidad para formar, revisar y perseguir racionalmente una concepción del bien. De estas se derivan dos intereses supremos: el de realizar sus facultades; y el de ejercer sus facultades, los cuales gobiernan la deliberación y la conducta en sociedad, con lo cual se garantiza que la moral no se quede a nivel abstracto. De ello se desprende un tercer interés de orden superior: proteger y promover su concepción del bien. La pregunta en este punto es si el conocimiento de los bienes primarios no vicia la argumentación de las personas morales. Para Rawls, los bienes primarios son condiciones sociales de la realización y el ejercicio de las facultades morales. La autonomía está dada en que las partes no se someten a principios a priori de justicia y en que se mueven por intereses de orden supremo. Constituyéndose este punto en un esfuerzo por superar los problemas que la crítica comunitarista había señalado al planteamiento de Teoría de la Justicia, y de igual manera, el punto que marca un acercamiento de Rawls a dicha posición.

Pero todo esto, a su vez, hace parte de los rasgos que caracterizan a una sociedad-bien-ordenada: poseer una concepción pública de justicia, estar constituida por personas morales libres e iguales, y tener estabilidad en el sentido de justicia. La primera hace referencia a la necesidad de que la concepción de justicia esté abierta a la discusión de la ciudadanía, haga parte de su vida social. La segunda, porque el ciudadano es concebido como persona moral y como tal debe ejercer y realizar sus facultades, una de las cuales es poseer un sentido de justicia efectivo. La tercera se entiende como la necesidad de que, fuese la que fuese, es decir, la que las partes elijan en una situación hipotética de argumentación sobre el particular, lo importante es que la sociedad mantenga y persiga un sentido de justicia como parte estructural de sí misma. Si no se cree en la justicia sería inútil todo tipo de discusión sobre la misma y toda eventual reforma o justificación institucional con base en ella.

Como queda claro, el engranaje de todo ello reside en la persona moral. La concepción de la justicia como equidad tiene en esa noción el fundamento de todo el edificio categorial. De allí por qué Rawls aclare las confusiones iniciales que parecían acercarla a la del "egoísta racional" del utilitarismo, y precise el contenido racional y pleno de la autonomía. Aclarando el alcance real de la persona moral, libre e igual, en una sociedad bien ordenada, teniendo en la justicia procedimental perfecta derivada de la posición original el puente metodológico que une ambos términos, pero simultáneamente mostrando que la 
proyección de la persona moral es el ciudadano de una sociedad justa y que la condición de ésta, a su vez, es la persona moral (Rawls, 1986).

\section{Republicanismo y filosofía hegeliana}

En su artículo La Discussion Républicaine du Libéralisme Moderne, Sylvie Messure y Alain Renaut, consideran el republicanismo en estrecha relación con el liberalismo político y su proyecto socio-político, describiéndolo no como un modelo opuesto sino como "una crítica interna de la modernidad política" (Messure, et. al., 2000 : 318). Ambos planteamientos tendrían, en este sentido, un suelo común: el sustrato liberal (le socle libéral), herencia del proyecto ilustrado y constituyente primordial de la modernidad, cuyos principios básicos en orden de importancia serían los siguientes: el principio de limitación estatal, el principio de soberanía popular, el principio de valorización del individuo y sus libertades, el principio de neutralidad estatal con respecto a la religión y la moral.

El surgimiento del pensamiento republicano se debe a una serie de problemas que Tocqueville (1998) descubrió en estos principios de la modernidad y que giran principalmente en torno al principio de valorización del individuo. En efecto, la preponderancia de este principio implica una desvalorización del de soberanía popular hasta el punto de generar una contradicción entre ambos. De la misma manera, el liberalismo corre el riesgo de producir un Estado tutelar cuando, con el objeto de evitar la atomización, trata de reintegrar la sociedad, lo cual implica una violación del primer principio y en general de los ideales modernos. Estos problemas parecen revelar, entonces, una dinámica autodestructiva en el interior de la modernidad. Cualquier teoría que se inscriba y tome como base la modernidad debe dar solución a estos problemas: en consecuencia, los republicanos pretenden introducir un cambio en la dinámica liberal-democrática que le evite caer en las contradicciones señaladas y le permita mantener intactos sus cuatro principios básicos.

Como salida a los problemas del liberalismo, Tocqueville (defensor de la democracia como un "progreso irresistible" y admirador de la "república americana”) propuso la recuperación de las libertades positivas o libertades de participación para salvar las libertades negativas (Messure, et. al., 2000 : 324). En esta misma línea, los pensadores republicanos buscan dar un giro republicano al liberalismo que resuelva los problemas aludidos respecto de los principios liberales mismos.

Esta concepción tiene varios problemas, que amenazan su puesta en práctica; el más importante de ellos consiste en hacer actuar a los individuos, volcados sobre ellos mismos, para mantener el proceso democrático. Debido a que en una sociedad liberal se tiende a convertir el individualismo en egoísmo, el individuo puede experimentar una fuerte apatía hacia el ejercicio de sus derechos de participación, al no percibir ninguna ventaja en retorno y acabar por 
desatender el ámbito de lo público. En otros términos, el reto que debe afrontar el republicanismo es cómo volver virtuosos a los ciudadanos sin recaer en las concepciones socio políticas premodernas (Patten, 1996).

En el intento de resolución de este problema, el republicanismo se ha divido históricamente en dos vertientes: el republicanismo anglosajón o neorepublicanismo (donde se destacan autores como Pettit, Skinner y Pocock) y la línea francesa o post-republicanismo, que suscriben Mesure y Renaut y Ferry.

El neo-republicanismo anglosajon

El republicanismo, que durante gran parte de la modernidad había permanecido desconocido y poco trabajado, fue reintroducido en el debate filosofíco político a mediados de los setenta por obras de Quentin Skinner (1990) y J. G. A. Pocock (1975), quienes realizaron una recuperación del pensamiento de Nicolas Maquiavelo y pretendieron encontrar en él una teoría contitutiva para un tercer movimiento surgido de la modernidad, alternativo tanto al liberalismo como al socialismo.

Skinner coloca el origen del ideal republicano en la filosofía moral romana y especialmente en los planteamientos de autores que constribuyeron a dar realce al ideal de la República, como fueron Livio, Salustio y Ciceron. Con posterioridad a Roma, este ideal fue recuperado en la Italia del renacimiento y de manera paradigmática por Maquiavelo, quien hizo uso de él para desarrollar su propuesta sobre la autonomía de las ciudades-estados de la época, como independientes y completamente ajenas al poder de la iglesia. Bajo la influencia de Maquiavelo, autores ingleses como James Harrington y John Milton adelantaron defensas acerca de los estados libres, que terminaron cristalizando en la independencia de los Estados Unidos (Skinner, 1998).

Skinner parte de la reformulación del ideal republicano, tal como aparecia expresado en la obra de Maquiavelo, para concluir que el republicanismo no podía interpretarse como un movimiento antimoderno en su esencia, puesto que la tradición maquiavelica en su integridad presenta una reivindicación de la libertad negativa (Berlin, 1969). La principal propuesta de Skinner sostiene que para construir el ideal republicano se debe tener como punto fundamental una serie de virtudes civicas dentro de las que figuraban entre otras:

[...] la igualdad, la simplicidad,la honestidad, la benebolencia, la frugalidad, el patriotismo, la integridad, la sobriedad, la adnegación, la laboriosodad, el amor a la justicia, la generosidad, la nobleza, la solidaridad y, en general, el compromiso con la suerte de los demás[...]. [pues] sólo gracias a la presencia de ciudadanos así dispuestos hacia su comunidad la república iba a tener la oportunidad de sobrevivir frente a contratiempos seguros (Gargarella, 1999 : 164). 
En esta línea también se encuentra Pocock, quien parte del rechazo a la separación, originada por el liberalismo, entre derecho y moral, que se constituirá en la base de una estrategia de regeneración moral, donde se desarrollara como ideal ético la idea de un humanismo cívico, y de esa manera recuperan la idea tocquevilliana de un republicanismo político, puesto que

La comunidad debe representar una perfecta unión entre todos los ciudadanos y todos los valores dado que, si fuera menos que eso, una parte gobernaría en el nombre del resto [consagrando así] el despotismo y la corrupción de sus propios valores. El ciudadano debe ser un ciudadano perfecto dado que, si fuera menos que eso, impediría que la comunidad alcanzase la perfección y tentaría a sus conciudadanos [...] hacia la injusticia y la corrupción [...] La negligencia de uno solo de tales ciudadanos, así, reduce las oportunidades de todo el resto, de alcanzar y mantener la virtud, dado que la virtud aparece ahora politizada; consiste en un ejercicio compartido donde cada uno gobierna y es gobernado por los demás (Pocock, citado por Gargarella, 1999 : 164).

En la actualidad el exponente más destacado del neo-republicanismo es Philip Pettit (2000), quien trata de solucionar el problema por medio del desarrollo de la noción de libertad como no-dominación. Con base en esto, considera que el republicanismo se define por tres condiciones. La primera de ellas es la no incertidumbre, la segunda es la no sumisión a los poderosos y la última es la no subordinación. Esas caracteristicas configuran la democracia republicana como una democracia de tipo disputatorio, que tiene como elementos esenciales el ser deliberativa, incluyente y reponsable, así como el primado de la virtud cívica entre los ciudadanos. En cuanto al aspecto procedimental, puede decirse que este tipo de democracia opera en los estados de derecho, especialmente en aquellos que se rigan por un sistema federal, sean bicamerales y existan mecanismos que puedan controlar el poder de las mayorías.

\section{El postrepublicanismo francés}

La línea francesa, que suscriben Messure, Ferry y Renaut, realiza una crítica directa a los anglosajones arguyendo que ellos han desviado el ideal republicano al convertirlo en una mera instrumentalización que tiende a corregir de manera formal y funcional los mencionados problemas del liberalismo. En abierta oposición a este modelo instrumental, los autores proponen un "republicanismo político" que crea estructuras políticas más participativas y democráticas a lo 
largo de toda la sociedad, para mostrar al individuo que su participación en la soberanía popular no es inútil y corresponde a su interés. La comprensión de este punto constituye la única garantía de funcionamiento del Estado de Derecho democrático. Es decir, solo la democracia realmente liberal puede corregir los defectos y patologías del individualismo.

Messure y Renaut exponen un primer intento de respuesta, desarrollado por los republicanos franceses en el siglo XIX, ${ }^{1}$ quienes, además de querer imprimir una inflexión original a los principios de la modernidad, buscan recoger y enriquecer la herencia de 1789 . De ella recogen la idea de la existencia de un tipo de derecho natural, no reducible al derecho positivo e independiente de cualquier tradición, absoluto y ahistorico, en lo que constituye una fuerte divergencia con el historicismo marxista que reduce el derecho a un simple epifenómeno de la lucha histórica de clases (Pettit, 2000).

Para estos republicanos el derecho se fundamenta en normas meta-históricas y meta-positivas, según las cuales lo que da legitimidad a una norma es su conformidad con las exigencias de la razón. Para el republicanismo, la razón sobrepasa la historia y define ideales atemporales; de ahí que se lo considere como un "racionalismo político". En acuerdo con este fundamento racional, los principios republicanos deben ser enseñables y la educación misma se convierte en elemento central dentro de su planteamiento: ella introduce al individuo en la sociedad para que pueda desenvolverse cívicamente dentro de la comunidad.

Otro elemento decisivo para el republicanismo es su original interpretación de la declaración de los derechos del hombre. Frente a la pregunta sobre cuáles son los valores jurídicos irreductibles a condiciones históricas de emergencia, los liberales toman partido por los "derechos libertades" (particulares), mientras los socialistas se la juegan por los "derechos créditos" (sociales). Los republicanos toman un camino alternativo que consiste en hacer aparecer al lado de las libertades fundamentales una consideración que afirma que "la felicidad común es la meta de la sociedad", aún cuando, a diferencia de los socialistas, no realizan una crítica de las libertades formales. Así pues, frente al derecho individual liberal, los republicanos rescatan una especie de "derecho social" entendido como un deber de ser solidario con la comunidad. Este concepto de solidaridad se debe entender en términos de "fraternidad"; de ahí que para los republicanos sea una obligación de la nación el asegurar la subsistencia de los menos favorecidos de sus integrantes. De este modo, con los derechos alternativos, lllamados derechos participación, el republicanismo supone que los derechos libertades garantizan, por su propio ejercicio, el respeto a las ideas de solidaridad y fraternidad (Ferry, et al., 1984).

1 Entre otros autores se destacan Charles Renouvier, Jules Barni y Jules Simon. 


\section{La Filosofía del Derecho de Hegel \\ Método y categorías centrales}

En realidad, tal como lo sostienen Findlay (1969), Kaufmann (1969) y Serreau (1972), Hegel jamás se interesó por explicitar la mecánica de su método. Más bien lo utilizaba en el estudio de los hechos históricos, desinteresándose por mostrar su fundamentación interna. En el prólogo a la Fenomenología del Espíitu (1966), escrito mucho después con la intención de servir de introducción a su amplio sistema filosófico, Hegel escribe: "El método no es, en efecto, sino la estructura del todo, presentada en su esencialidad pura" (Hegel, 1966 : 32). Con ella quería explicitar que su método no era sino la abstracción del proceso histórico, el cual había observado que se desarrollaba según esa triádica manifestación de tesis, antítesis y síntesis, grosera esquematización posterior jamás utilizada por el pensador de Stuttgart.

La dialéctica pretende representar metódicamente la dinámica de la historia, la cual se puede ilustrar como el consecutivo desarrollo de momentos, que se niegan unos a otros, subsumiéndose. Tal es la razón de que a la dialéctica se la haya denominado también la negación de la negación (Konstantinov, 1965). Es el mismo movimiento de la historia, que parece desarrollarse triadicamente, el origen de la dialéctica hegeliana. Hegel bosquejó cada momento de su método dejando una idea clara de lo que cada uno significaba para él, sin preocuparse de categorizarlo en forma exhaustiva con lo cual aquella puede descomponerse en tres momentos distintos: el momento abstracto, el dialéctico y el especulativo (Serreau, 1969).

El momento abstracto es el momento del entendimiento, de la afirmación. Se caracteriza por sus nociones fijas y definidas y la distinción e independencia de cada una con respecto a las otras, lo cual es imprescindible y necesario para trabajar conceptualmente una materia. Historicamente es el momento de arranque de una época donde hay un orden aparente y claro de los diversos factores que la constituyen. El momento dialéctico es el momento de la negación, donde todo se relativiza. Aquí se hace evidente la tendencia implícita de nuestras nociones a transformarse en otras, haciendose mas ricas, concretas y profundas. En por lo mismo el momento de la contradicción, presente siempre en el entendimiento y que se hace explícita en la dialéctica cuando las nociones tienen que dejar su rigidez y explicarse ayudándose de sus correlativos o complementos.

Hegel no entiende la contradicción como un accidente subjetivo de carácter linguístico o conceptual: no es la contradicción vaga y equívoca sino la contradicción interna que relativiza y cuestiona, presente en la realidad objetiva y por lo mismo fuerza motriz de la vida, la sociedad y la historia. Como relativización y negación de lo dado su fórmula se sintetiza en los períodos de transformación radical, de subversión social. El momento especulativo o de la razón, integra los dos anteriores. Las nociones definidas del entendimiento y las correlaciones señaladas por la dialéctica como necesarias son asumidas en una nueva racionalidad que las 
integra y conserva. La razón no hace desaparecer las contradicciones sino que las asimila y las mantiene presentes en una nueva unidad.

La dialéctica hegeliana va de la mano con tres categorías determinantes. La primera es la de totalidad: "Lo verdadero es el todo" (Serreau, 1969 : 16). Sin duda este concepto resume la proposición metodológica del hegelianismo. La comprensión del fenómeno solo se alcanza abarcando todas sus manifestaciones, desde todos los puntos de vista posibles. Es, además, el imperativo del tercer momento de la dialéctica hegeliana: alcanzar la integración de todos los compuestos del hecho, desde el mayor número de perspectivas. Pero es también el supuesto de que ello se logra mostrando la relación entre el todo y la parte, su condicionalidad recíproca e, incluso, como dice Lukács, el "dominio omnilateral del todo sobre las partes” (Lukacs, 1975 : 28). De allí por qué en la dialéctica hegeliana el momento especulativo suponga las otras categorías para ser comprendido adecuadamente y poderse implementar como un método auténtico de interpretación y conocimiento.

Una segunda es la de la identidad sujeto-objeto. Hegel afirma, en el Prólogo citado: "Según mi modo de ver [...] todo depende de que lo verdadero no se aprehenda y se exprese como sustancia, sino también y en la misma medida como sujeto" (Hegel, 1966 : 15). Una de las grandes preocupaciones hegelianas fue siempre el divorcio existente entre el hombre y su mundo. El ser humano vive una situación de divorcio entre él y su entorno, de enajenación recíproca. El objetivo de la filosofía, del derecho y del Estado, y de la historia, es lograr alcanzar la reconciliación entre el hombre y el mundo, conceptual, material y espiritualmente.

En general, el sistema hegeliano y cada uno de sus tópicos es la realización de sus categorías articuladas metódicamente. Las tres grandes divisiones de su filosofía ilustran ese punto: la Ciencia de la Lógica (Hegel, 1968) (estudio de la Idea en el medio abstracto del pensamiento), la Filosofía de la Naturaleza (Idea en su auto-alienación y auto-exteriorización ) y la Filosofía del Espíritu (Idea en su regreso a sí misma desde su auto-alienación) patentizan esa aseveración. Si se toma la Fenomenología del Espíritu como preludio temprano de la Enciclopedia de las Ciencias Filosóficas observamos que aquella describe sistemáticamente los diversos tipos de conciencia que la humanidad ha agotado para conquistar su conciencia individual, su conciencia social y su conciencia histórica (Goldman, 1978).

\section{Alienación y reconciliación}

Pero es la tercera, la de alienación, la categoría vertebral de la filosofía hegeliana, resultado de un largo proceso personal cuyos antecedentes reposan en los escritos juveniles de Hegel, así como en apariciones esporádicas del mismo en algunas escuelas económicas o filosóficas que lo antecedieron (Hegel, 1978). En sus inicios, el concepto se encontraba implícito junto al de religión positiva que Hegel desarrolla durante el "Periodo de Berna". Positividad significaba una institución o un complejo ideológico que se contraponía a la subjetividad humana 
(Marcuse, 1976). En Hegel, el problema de la alienación constituye el eje básico tanto de la relación como de la situación del hombre respecto del mundo. Su tratamiento del asunto está referido a la realización del sujeto-objeto idéntico en la historia, es decir, la superación de la alienación y la reconciliación con el proceso histórico, con la sociedad y consigo mismo (Lukacs, 1975).

La historia de la idea, desde su origen cosmológico, así como la del género humano (el Espíritu, en Hegel) es, pues, la historia de su alienación, de su divorcio, de su desgarramiento frente al mundo (Lefebvre, 1976). Su ideal, su aspiración permanente, es alcanzar la libertad auténtica teniendo como punto de partida la superación de esta alienación, en otras palabras; la reconciliación y la recuperación de su dominio sobre el mundo. En la Fenomenología del Espíritu, en 1806, la alternativa que Hegel concibe para lograrlo es la razón que, como saber absoluto (Palmier, 1977), le permite tomar conciencia de esta situación y, a través del reconocimiento integral de la historia, recuperar conceptualmente la dimensión total, individual, social e histórica, perdida. La comprehensión totalizante del sujeto permite resumir el desarrollo que hasta ese momento se había presentado extraño y ajeno al individuo, reasumiéndolo retrospectivamente (Serreau, 1972).

Así pues, La Fenomenologia del Espíritu y, en general, toda la sistematización filosófica hegeliana, marcan para la humanidad la toma de conciencia del hombre sobre sí mismo, su sociedad su historia, al tiempo que constituyen un reconocimiento de la totalidad del proceso histórico humano, en la multiplicidad de sus manifestaciones. El método de la Fenomenología se basa en una unidad de las consideraciones históricas y sistemáticas, en la convicción de que hay una profunda conexión interna entre la sucesión lógico-metodológica de las categoría, su dialéctico explicitarse unas de otras y el desarrollo histórico de la humanidad. Para Hegel, todo el Espíritu (o sea el hombre, su sociedad, su historia) tiene una historia real. El camino que tiene que recorrer cada individuo desde la conciencia vulgar hasta la filosófica es al mismo tiempo el camino del desarrollo de la humanidad, el resumen del abreviado de todas las experiencias de la especia humana y representa como tal, y desde este punto de vista, el proceso histórico mismo (Lukacs, 1978).

La tarea de la Fenomenología será entonces la apropiación de las experiencias de la especie por el individuo. De allí que historia y sistema se encuentren en una conexión metodológica rigurosa y necesaria. La Fenomenología del Espíritu se divide en tres partes: el espíritu subjetivo, el objetivo y el absoluto. En el espíritu subjetivo el punto de partida será necesariamente el natural e inmediato del individuo. $\mathrm{Al}$ avanzar, el individuo recorre singularmente desde la percepción inmediata de la realidad objetiva hasta su racionalidad, recorriendo todas las etapas del desarrollo histórico de la humanidad. Aquí, el individuo reconoce progresivamente el carácter real de la sociedad y de la historia como algo hecho por los hombres mismos colectivamente (Lukacs, 1978). 
Con esta certidumbre el hombre entra en el espíritu objetivo. La conciencia conoce ahora la historia como historia real, la sociedad y su desarrollo no ya como cosa muerta ni como destino misterioso sino como producto de la actividad práctica misma de los hombres. En este segundo estadio, tenemos ante nosotros la historia real en su concreta totalidad social. Desde aquí la conciencia individual llega al nivel del conocimiento absoluto. Desde este nivel, el del espíritu absoluto, el hombre lanza una mirada retrospectiva a toda la historia dada donde reconoce los diversos momentos del proceso como propios, logrando así superar el desgarramiento con la realidad individual, social e histórica y la reconciliación con su entorno en general.

Detengámonos ahora en tres momentos que conforman el Espíritu objetivo. El primero, el "El espíritu verdadero: la eticidad", que trata sobre la sociedades antigua y su posterior disolución y decadencia, describirá cómo el desarrollo del derecho positivo ejercerá sobre esta una acción disolvente sobre su eticidad inmediata dando así nacimiento a un sistema jurídico abstracto, originando la más primitiva forma de alienación donde el sujeto, como especie, tiene que enajenarse, a través de relaciones sociales cada vez más ricas, para reconocerse a sí mismo progresivamente. El segundo momento, el Espíritu Extrañado de sí mismo: la cultura, describirá la disgregación de la Edad Media a través de la monarquía absoluta y, especialmente, el proceso revolucionario francés, síntesis representativa y contradictoria de todo el desarrollo moderno. La Revolución Francesa expresa en la libertad absoluta y el terror el desbordamiento histórico del espíritu y de la idea de libertad.

Finalmente, el tercer momento, El espíritu cierto de sí mismo: la moralidad es la crítica, sarcástica desde su título, de la filosofía práctica kantiana y el intento fallido de la burguesía revolucionaria de superar las contradicciones sociales, políticas e históricas a través de la figura de una moral autónoma que funda un contrato social y un derecho racional con pretensiones universales (Palmier, 1977). Esto explica, precisamente, que en 1806 Hegel no vea una alternativa histórica plausible y que, por tanto, la superación de la alienación y la reconciliación con el entorno tengan que darse a través de las figuras ideológicas del espíritu absoluto, arte, religión, conciencia histórica, al no darse una figura objetiva que garantice socialmente la realización plena de la libertad.

Pero la alternativa de la Filosofía del Derecho, obra publicada ya muerto Hegel en 1830, ofrece una proyección radicalmente diferente (Hegel, 1968). Aquí el instrumento de superación de la alienación no será ya la razón concretada en el saber absoluto sino en el Estado, con mayúscula, encarnación del espíritu objetivo. El Estado permite reconciliar no solo al hombre sino a la sociedad moderna. Ya no se trata de la salida que históricamente se imponía en 1806, la del saber absoluto, sino la alternativa real que el Estado ya constituía a finales de la década de 1820. 
El Estado se evidencia como la herramienta por excelencia para la reconciliación del hombre con la sociedad, de la razón con la historia, de la idea con el mundo. El Estado y todas las esferas que en torno a él gravitan (en especial el derecho pero, también, la cultura, la religión o el ethos popular) resultan para Hegel el medio eficaz para la superación real de la alienación (Hegel, 1974). El saber absoluto y el Estado permiten a la humanidad darse cuenta de que es ella quien se ha creado a sí misma como individualidad, como sociedad y como historia y que la apariencia de autonomía de estos dominios no era sino una falsa ilusión que las circunstancias habían propiciado (Palmier, 1977).

\section{Recepción de Hegel y el Republicanismo}

\section{Lecciones sobre la Filosofía del Derecho}

Las últimas lecciones que dicta Rawls sobre filosofía moral en Harvard University y que son compiladas y editadas por una de sus asistentes, Barbara Herman (2001), son sobre la filosofía del derecho de Hegel y el concepto de eticidad y datan, según prologa la compiladora, de 1991. Su importancia va a ser decisiva, a nuestro modo de ver, pues ello explica, como la misma Herman lo plantea, tanto "el puente entre el pensamiento moral kantiano y el liberalismo de la propia obra de Rawls" (Herman, 2001 : 15) como el giro republicano que se consolidará con la publicación de Liberalismo Político, dos años más tarde y que se consolidará después con "The Idea of Public Reason Revisited" (Rawls, 1999), prácticamente el último texto que escribe, y más tarde con otro libro editado por otro de sus asistentes, La Justicia como Equidad: una Reformulación (2001).

En efecto, las lecciones sobre Hegel básicamente abordan dos temáticas: de una parte, la Filosofía del Derecho, donde se destaca un punto que empieza a ser clave en la obra de Rawls a partir de este momento y que se afianza, precisamente, en La Justicia como Equidad: una Reformulación: la categoría de reconciliación (Rawls, 2001a). Recordemos que la reconciliación está íntimamente relacionada con la categoría de alienación y que es prácticamente consustancial a esta. La historia prácticamente se concibe como un proceso cósmico de desgarramiento donde la idea de libertad de aliena primero en la naturaleza y posteriormente en la historia misma de la humanidad (el espíritu, para Hegel) donde, a su vez, en un triádico proceso de alienación, el del espíritu subjetivo, el objetivo y el absoluto, el hombre supera la alienación y se reconcilia con la idea de libertad. Esta, como vimos, es la alternativa que adopta la Fenomenología del Espíritu en 1806.

El giro que significa la Filosofía del Derecho, en donde el Estado es la figura social e histórica que permite superar la alienación, mantiene el sentido permanente de la reconciliación, a saber: la superación de la alienación y, por ende, el logro de la verdadera emancipación. La reconstrucción de la Rechtsphilosophie en 
las Lecciones reconstruye las figuras hegelianas de la voluntad libre, la propiedad privada y la sociedad civil que constituyen en Hegel la crítica al contractualismo en la perspectiva de la superar la alienación que el pensamiento liberal ha propiciado con estas figuras y lograr así la reconciliación integral que no se alcanza a través de ellas. Sin duda, Hegel pondrá de presente que el contractualismo oculta una condición original de injusticia entre poseedores y desposeídos, y pretende ocultar esta ecuación inequitativa a través de la supuesta igualdad formal del contrato, que el reconocimiento legal de la propiedad privada y consolidación de la sociedad civil pretenden mimetizar.

La reconstrucción conduce a la figura de la sittlichkeit que en la forma del Estado constituirá para Hegel la reconciliación histórica de la humanidad. El Estado no solo permite conciliar la sociedad tradicional con la sociedad civil burguesa que tiende a destruirla sino que se representa igualmente el momento de reconciliación total a nivel social e histórico, es decir, la superación de la alienación en ese momento determinado. Reconociendo en Hegel un crítico del liberalismo, un liberalismo formal y vacío, Rawls explorará una tercera alternativa a través de la propuesta de Rousseau y Kant, de una "fe razonable" en orden a concebir el Estado "como una totalidad concreta, una totalidad articulada en sus grupos particulares” (Rawls, 2001a : 380), en línea prácticamente con una concepción de deliberación republicana, de proyección cosmopolitita adicionalmente. El liberalismo político que Rawls opondrá al liberalismo de mayorías adquiere aquí su consistencia definitiva.

Pero más allá de esto, es imposible negar la asimilación directa que Rawls hace de la categoría de reconciliación e, indirectamente, de la de alienación, estrechamente ligada a aquella. Con lo cual la cercanía de Rawls no solo con Hegel sino con el joven Marx y el marxismo heterodoxo (Habermas entre estos) encuentra unos puentes bastantes significativos. Además, se filtra en su planteamiento la noción de conflicto como un elemento constitutivo de la vida social y que justifica, puntualmente, la necesidad de mecanismos consensuales que permitan superarlo.

\section{Republicanismo y Liberalismo Político}

\section{El republicanismo razonable}

La obra del 93 culmina una larga serie de revisiones que Rawls introduce a la versión original de su Teoría de la Justicia. Political Liberalism (1993) recoge el núcleo de aquellas e integra una nueva visión de la justicia que este ha calificado de concepción política de la misma, la cual constituye un giro sustancial que sin duda se origina en las críticas formuladas por el comunitarismo al planteamiento original. En efecto, el libro formula varios cambios de fondo, siendo el 
más importante la distancia que toma frente al kantismo y la definición de un constructivismo no comprehensivo, como columna metodológica de su teoría. Pese a que mantiene varios conceptos que Rawls siempre ha sostenido que se han inspirado en la filosofía moral kantiana (la concepción original, el velo de ignorancia, la noción de autonomía racional) (Höffe, 1988), ahora enfatiza las diferencias que distinguen su concepción de la justicia del sistema de Kant en una clara estrategia por limar asperezas con los comunitaristas para quienes el universalismo y formalismo de la filosofía moral kantiana es el origen de no pocos conflictos y contradicciones morales de la modernidad.

La segunda en importancia, desde el punto de vista de la filosofía política, es la conversión de su justicia como equidad en una concepción política de la justicia (Agra, 2004)que constituye la esencia misma de su idea del liberalismo político. La implicación de ello es, sin duda, el carácter universal que puede proyectar el contexto: la concepción de la justicia que inspira a los regímenes constitucionales democráticos tiene una validez universal, en cuanto que el procedimiento de selección y legitimación de los principios que rigen su estructura básica responde a un mecanismo de argumentación válido en todas las latitudes, si bien cada procedimiento está mediado por las condiciones particulares de cada situación.

Además de estos cambios, Rawls introduce dos nociones que complementan su concepción política de la justicia como liberalismo político: la del consenso entrecruzado (overlapping consensus) y la de la razón pública. La primera para describir el objetivo final de su liberalismo y, la segunda, para mostrar los mecanismos que garantizan los principios de justicia en un régimen constitucional. Los dos representan el énfasis social de la teoría rawlsiana y confirman su distanciamiento de todas las teorías abstractas de la filosofía moral y política contemporánea. El pragmatismo de la tradición anglosajona se revela, con esto, en toda su fuerza y proyección y de allí, sin duda, el calificativo que se le ha dado de "pragmatización del proyecto liberal" rawlsiano (Thiebaut, 1994).

\section{Consenso entrecruzado y razonabilidad}

El consenso entrecruzado (overlapping consensus) constituye el constructo principal de la interpretación rawlsiana sobre una democracia consensual-constitucional (Rawls, 1993), viene a ser el instrumento procedimental de convivencia política democrática. Este liberalismo procedimental, cuya fuerza y proyección reside en la flexibilidad y transparencia del procedimiento político de argumentación e interrelación ciudadanas, supone la existencia en el seno de la sociedad de varias doctrinas omnicomprehensivas razonables, cada una con su concepción del bien, compatibles con el pluralismo que caracteriza a los regímenes constitucionales.

Sólo una concepción política de la justicia puede servir de base al consenso entrecruzado puesto que en ella los principios y valores políticos constitucionales son los suficientemente amplios como para integrar y superar los valores que 
entran en conflicto. Esos macrovalores, también llamados virtudes cooperativas de la vida social (la razonabilidad, el sentido de equidad, el espíritu de compromiso y la reciprocidad), gobiernan el marco de la vida social y especifican los términos fundamentales de cooperación social y política que este liberalismo consensual intenta sintetizar y sobre los cuales los ciudadanos, desde su plena libertad de conciencia y perspectiva omnicomprehensiva, concilian con sus valores políticos y comprehensivos particulares. Con lo que se hace manifiesto el giro que Rawls está dando hacia el republicanismo.

Ello nos conduce al objetivo cardinal de la versión rawlsiana de su liberalismo político que es lograr un consenso entrucruzado de doctrinas onmicomprehensivas razonables sobre los principios de justicia, en tanto macrovalores reguladores de la estructura social. La concepción política que rige la estructura básica de una sociedad no requiere ser monocomprehensiva. Su estabilidad no depende de una visión sistemáticamente unificada sino necesariamente pluralista. Cuando se adopta este marco de deliberación, los juicios convergen lo suficiente como para que la cooperación política, sobre la base del mutuo respeto, pueda mantenerse. Tal concepción política constituye un marco de deliberación y reflexión que permite buscar acuerdos políticos sobre cuestiones de justicia y aspectos constitucionales básicos para toda la sociedad.

La concepción de justicia más razonable para un régimen democrático es, por lo mismo, ampliamente liberal. Cuando un consenso entrecruzado mantiene y alienta esta concepción, ella no es vista como incompatible con valores fundamentales, morales o psicológicos, pues las virtudes de cooperación política que posibilita un régimen constitucional son y deben ser macrovirtudes de tal amplitud, por lo que las virtudes cooperativas están llamadas a ocupar un lugar central dentro de dicho modelo, manifestándose en este punto la influencia que Rawls recibe de la propuesta de Skinner. El consenso, fiel a su carácter constructivista, debe cumplir un determinado proceso procedimental. Una primera etapa la constituye lo que Rawls denomina la etapa constitucional. Esta etapa satisface los principios procedimentales de convivencia política, autonomía y neutralidad, que como tales se aceptan, sin incluir ni suponer ideas fundamentales sobre la sociedad y la persona. Define, en últimas, los procedimientos políticos de un sistema constitucional democrático.

La segunda etapa es la del consenso entrecruzado, en el nivel de la sociedad en general, que se logra una vez concretado el constitucional. El contenido del mismo dependerá, sostiene Rawls, de que sus principios estén fundados en una concepción política de la justicia, tal como podría ser descrita por los principios de justicia. En cuanto a su proyección, esta trasciende los principios políticos que instituyen los procedimientos democráticos para incluir principios que cubran la estructura básica como un todo. Para ello se requieren propuestas legislativas y ciudadanas que garanticen un mínimo de bienes sociales primarios 
y no solo libertades políticas, y, por tanto, los grupos políticos deben plantear alternativas que cubran la estructura básica y explicar su punto de vista en una forma consistente y coherente ante toda la sociedad.

Las fuerzas que presionan porque el consenso constitucional devenga un consenso entrecruzado son los grupos que acuden al foro público de la discusión política, convocando con ello a otros grupos rivales a presentar sus perspectivas. Esto hace necesario, en términos racional-instrumentales, romper el estrecho círculo de sus concepciones específicas y desarrollar su concepción política como justificación pública de sus posturas. Al hacer ello, deben formular puntos de discusión sobre la concepción política de la justicia, lo 1cual permite la generalización del debate y la difusión de los supuestos básicos de sus propuestas.

\section{Razón pública y deliberación razonable}

La concepción rawlsiana del liberalismo político se cierra en la noción de razón pública que complementa las dos anteriores (Rawls, 1996), introduciendo una figura que retoma la del equilibrio reflexivo, pero en una proyección socio-institucional equivalente de aquella. Rawls comienza recordando que la prioridad de la justicia sobre el derecho, la eficacia y el bienestar es esencial para toda democracia constitucional. Tal prioridad significa que los principios de justicia imponen límites a los modelos de vida permisibles y los planes de vida ciudadanos que los transgredan no son legítimos ni moralmente justificables. Define una noción de neutralidad procedimental sin acudir a valores morales legitimatorios y sin ser ella misma procedimentalmente neutra.

La sociedad política posee, además, una idea civil del bien que realizan los ciudadanos en tanto personas y en tanto cuerpo corporativo, manteniendo un régimen constitucional justo y conduciendo en el marco del mismo sus asuntos privados. Los ciudadanos comparten así un fin común: sustentar instituciones justas que les proporcionan un bien específico como individuos (Dworkin, 1994). Pero no es una razón abstracta, y en ello reside la diferencia con la noción ilustrada de la razón. Posee cuestiones y foros concretos donde la razón pública se expresa y manifiesta. En una sociedad democrática esta razón pública es, primero que todo, una razón ciudadana, donde sus miembros como cuerpo colectivo son quienes, como ciudadanos, ejercen un poder político y coercitivo, promulgando leyes y enmendando su constitución cuando fuere necesario. El alcance de la razón pública no cobija toda la política sino solo los esenciales constitucionales y la justicia básica de sus estructuras. Tampoco se aplica a las deliberaciones personales sobre cuestiones políticas o a las reflexiones gremiales sobre la sociedad.

El ideal de la razón pública no solo gobierna el discurso público sobre estas cuestiones sino, también, la consideración ciudadana sobre ellos. La connotación de la ciudadanía democrática impone el deber moral de explicar de qué 
manera los principios y políticas que se defienden pueden ser congruentes con los valores políticos de la razón pública. La razón pública no se circunscribe al foro legislativo sino que es asumida, también, por la ciudadanía como criterio de legitimación. El ciudadano afirma el ideal de razón pública, no como resultado de compromisos políticos, sino desde el seno de sus propias doctrinas razonables y de la concepción de justicia política, en tanto macrovalores reguladores de la estructura social.

El contenido de la razón pública es, pues, el contenido de los principios de la justicia o de la concepción de justicia concertada públicamente, en tanto especifica derechos, libertades y oportunidades, asignándoles una prioridad lexicográfica y garantizándoles las medidas necesarias para cumplirlas, independientemente de todo tipo de doctrinas omnicomprehensivas.

Aquí se puede apreciar que la idea civil de bien configura un acercamiento a la propuesta del humanismo cívico de Pocock, con lo que se demuestra que ambas corrientes del neo-republicanismo ejercen influencia en la evolución de Rawls. Sin embargo, dichas recepciones generan una tensión interna en el planteamiento, puesto que estas influencias presentan dos campos divergentes. Por un lado se encuentra la propuesta de las virtudes a la manera de Skinner, que buscan introducir ciertos elementos de corrección para la dinámica liberal, con los que no se contaba en un principio, que sólo tienen un papel y una función instrumental; de otro lado, está el planteamiento de Pocock, que presenta una etitización del mundo de la vida, corriendo el riesgo de un retorno a concepciones premodernas.

\section{Reformulación de justicia como equidad}

La razón pública revisitada

Quizás el último texto que escribe Rawls, ya que el siguiente es más bien una edición que prepara uno de sus asistentes, Erin Kelly, y que Rawls logra revisar solo parcialmente, es la de la razón revisitada (Rawls, 2001b). Esta reelaboración de "La idea de razón pública" de Liberalismo Político adquiere en momentos un tinte marcadamente hegeliano que recuerda el talante de la Filosofía del Derecho de Hegel, en especial cuando Rawls explora dimensiones tan puntuales de la vida cotidiana como las de la religión y la familia en su propósito de exponer las raíces más profundas de la razón pública.

Rawls comienza explicitando la estructura de la razón pública desde cinco aspectos: las cuestiones políticas fundamentales; los funcionarios y candidatos públicos que la personifican; las concepciones políticas razonables que la componen; la aplicación de estas a la promulgación de las leyes; y el control ciudadano que se ejerce sobre ellas. Todo lo cual se articula con el foro político público que, a su vez, se puede dividir en tres partes: las decisiones judiciales; el discurso de los funcionarios públicos; y el discurso de los candidatos a cargos públicos. Rawls 
distingue este foro público de la cultura de base de la sociedad civil en cuento la primera no se aplica a la segunda y más bien establece su origen en una concepción de ciudadanía democrática de una democracia constitucional. Rawls, además, califica a esta última como una democracia deliberativa que cumple a su vez tres condiciones: primero, posee una idea de razón pública; segundo, se enmarca en unas instituciones democráticas constitucionales; y tercero, es el apoyo que esto tiene entre los ciudadanos. Y añade: "La deliberación pública se hace posible cuando se reconoce como una característica fundamental de la democracia y cuando se libra de la maldición del capital" (Rawls, 2001b : 163).

Rawls precisa inmediatamente el contenido de la razón pública especificando que este viene dado por una "familia de concepciones política de justicia", nunca por una sola, que necesariamente incluyen como características comunes un listado de derechos, libertades y oportunidades, la prioridad política de estos y, finalmente, medios que garanticen la realización efectiva de aquellos entre todos los ciudadanos. La razón pública no puede fijarse ad eternum: reconoce otras concepciones, incluso "más radicalmente democráticas que la liberal" (Rawls, 2001b : 166) y puede contener nociones tradicionales de bien común y solidaridad, si bien aclarando que la razón pública se distingue igualmente de la razón y los valores seculares. En el cuadro de una concepción política de justicia así definida discurre pues la argumentación pública. Rawls posteriormente precisa las relaciones entre religión y razón pública, estipulando que, en todo caso, la base la proporciona la constitución política como el contrato básico para mantener la paz civil y nunca puede revertirse esa relación a favor de presupuestos religiosos de ninguna índole. La tolerancia y la libertad de conciencia son centrales e irrenunciables en una democracia constitucional (Rawls, 2001b : 175).

Rawls analiza enseguida la cultura política pública, particularmente en lo que se refiere al debate público que gira en torno a doctrinas generales razonables, es decir, que planteen "razones políticas apropiadas" públicamente y no solo a su doctrinas comprehensivas. Para precisar esto, Rawls distingue entre cultura política pública y cultura de base, como ya lo había planteado en Liberalismo Político (Rawls, 2001b : 176). El razonamiento y la justificación públicas definen la cultura política pública frente a la cultura política de base que se antoja particular y especifica frente a la primera. Tal parece ser el sentido de la estipulación, en cuanto una argumentación, pese a pertenecer a una cultura política de base, solo es pública cuando efectivamente acepta manifestarse sobre concepciones de proyección y alcance público, no privado, de justicia, verificable en hechos sujetos al escrutinio y el examen públicos, cumpliendo así unos mínimos de civilidad presupuestos en la estipulación misma. De ahí la diferencia con otras dos formas de expresión no públicas: la declaración que 
no aspira a ser compartida conjuntamente y la conjetura sobre lo que creemos que son las otras doctrinas básicas (Rawls, 2001b).

Rawls aborda finalmente el tema de la familia como parte de la estructura básica de la sociedad, sin duda un tema polémico desde la perspectiva del liberalismo convencional pero que ya desde Teoría de la Justicia estaba claro, en cuanto la pretensión de regulación de los principios de justicia abarca ámbitos privados como la familia monogámica. Aquí el argumento es simple y directo: "La familia forma parte de la estructura básica de la sociedad porque una de sus principales funciones es servir de base de la ordenada producción y reproducción de la sociedad y de su cultura de una generación a otra" (Rawls, 2001b : 181).

Además, la justicia política de una sociedad tiene que aplicarse a la familia pues no de otra manera se garantiza que la condición de mujeres e hijos esté adecuadamente regulada por principios democráticos concertados, lo cual es común a toda asociación (universidades, gremios, sociedades científicas), inclusive a las iglesias, en cuanto aquella les impone "restricciones esenciales" que no pueden ignorar, sin vulnerar por supuesto sus respectivas jurisdicciones particulares de autonomía (Rawls, 2001b : 183). Las mismas desigualdades de género solo pueden regularse si se concibe a la familia como parte de la estructura básica.

\section{Cuatro papeles de la filosofía política}

En las modernas sociedades liberales se presenta la explosión de una serie de problemas, que plantean un reto a todo el proceso de conformación y estructuración social. Para Rawls existen cuatro problemas principales a los que deben hacer frente las sociedades, que determinan cuatro papeles básicos que debe cumplir la filosofía política en la actualidad. Los cambios que efectúa el autor en su obra obedecen a la aceptación de estos problemas y la necesidad que tiene la filosofía política de dar una respuesta coherente a este tipo de problemática.

El primer papel que es considerado por Rawls es el llamado papel práctico de la filosofía política; nace del conflicto político presente en la actuales sociedades y de la necesidad de lograr alguna solución para el problema del orden, "una de las tareas de la filosofía política -su papel práctico, por así decir- es fijar la atención en las cuestiones profundamente disputadas y ver si, pese a las apariencias, puede descubrirse alguna base subyacente de acuerdo filosófico y moral" (Rawls, 2002a : 23), es decir, en este papel la filosofía política se encuentra dedicada a detectar una serie de cuestiones básicas que generan en el interior de la sociedad ciertos conflictos de difícil solución.

Una vez han sido detectados, la filosofía política debe entrar a analizar su origen y encontrar una base que permita articular un acuerdo filosófico y moral, que logre asegurar la cooperación y el respeto mutuo en el interior del entramado social. Rawls reconoce que lograr este suelo común no resulta ser una tarea fácil, por lo que la filosofía política debe en la mayoría de los casos contentarse 
con una tarea más modesta: buscar limitar el campo de divergencia al mínimo posible para generar un acuerdo político que esté en condiciones de garantizar los elementos anteriores.

También existe una serie de conflictos que se enmarcan en el seno de los diversos grupos que conforman la sociedad. Estos grupos tienden a no sentirse del todo incluidos dentro de la dinámica general de la sociedad por lo que se genera una serie de crisis de identidad es así como las visiones comprensivas muchas veces no encuentran su anclaje dentro del entramado social. Apuntando a este grupo de problemas se encuentra el segundo papel de la filosofía política, el de orientación, que reconoce la necesidad que tienen los miembros de cualquier sociedad de una "concepción que les permita entenderse a sí mismos como miembros que poseen un determinado estatus político -en una democracia, el de ciudadanos iguales- y les permita entender cómo afecta dicho estatus a la relación con su mundo social" (Rawls, 2002a : 25).

En esta etapa el desarrollo de la filosofía política como un ejercicio de la razón debe cumplir con la tarea de determinar "los principios que sirven para identificar esas diversas clases de fines razonables y racionales, y mostrando de qué modo son congruentes esos fines con una concepción bien articulada de sociedad justa y razonable"(Rawls, 2002a : 25). Como intermediación necesaria para lograr como meta primordial, "contribuir al modo en que un pueblo considera globalmente sus instituciones políticas y sociales, y sus objetivos y propósitos básicos como sociedad con historia -como nación"(Rawls, 2002a : 24). En síntesis, el papel orientador de la filosofía política está encaminado a reconocer la diversidad social en todas sus facetas y generar un proceso de construcción de identidad que lleve a todas esas diferentes visiones a reconocerse como integrantes de un núcleo mayor.

El individuo presenta a su vez una serie de problemas y desajustes con el conglomerado social, pues en ellos existe una serie de frustraciones y descontentos que repercuten en la formación de una crisis personal de identidad. Esta crisis surge principalmente de dos realidades sociales, la primera de las cuales es el pluralismo razonable, que presenta un amplio menú de diferencias en las concepciones personales sobre lo social y lo político, que por lo general resultan ser profundas e irreconciliables; el segundo foco de descontento se ubica en la arbitrariedad que existe en cuanto a la sociedad a la que se pertenece. Efectivamente, los individuos no eligen pertenecer a determinado grupo social; simplemente se encuentran en una determinada sociedad particular y en un tiempo histórico dado.

Para responder a este bloque de problemas, Rawls (2002a) plantea un papel de reconciliación para la filosofía política, asumiendo argumentos hegelianos. Aquí lo que se busca es mostrar la racionalidad que existe en la historia y en el desarrollo de las instituciones sociales, y con esto mostrar a los ciudadanos 
lo real que son estas diferencias y la riqueza que aportan a la sociedad en su conjunto. Con este proceso se busca generar en los ciudadanos una aceptación y afirmación de su mundo social, evitando que se produzca una resignación a éste. Rawls recomienda cierta prudencia en la comprensión de este papel, pues corre el riesgo de ser utilizado para la preservación y continuidad de un orden injusto (Rawls, 2001c).

El último problema al que hace referencia Rawls también se origina en el pluralismo razonable que representa una limitación a lo que se puede realizar en la sociedad, pues implica la existencia de gran cantidad de propuestas y proyecciones que no van a poder efectuarse, lo que podría tener repercusión en diversos tipos de crisis y frustraciones (Rawls, 2002a : 27). Por este hecho la filosofía política debe adelantar una investigación sobre los límites de la teoría, revelando la frontera entre lo posible y aquello que no puede hacerse, y de esta manera reforzar y fortalecer la creencia de que se puede alcanzar un orden político lo más perfecto posible, pese a los límites que la realidad imponga.

\section{Razonabilidad y estabilidad}

La otra reflexión que marca el giro de Rawls se da en relación con el estudio del la noción de estabilidad y su papel dentro de las modernas sociedades liberales, especialmente aquellas donde impera un pluralismo razonable. Para el estudio de la estabilidad comienza realizando un balance de Teoría de la Justicia donde se rescata que "el cometido de los representantes es seleccionar los principios que mejor garantizan el bien de la personas a las que representan así como sus intereses fundamentales, dejando de lado las psicologías especiales" (Rawls, $2002 \mathrm{~b}$ : 245), todo con miras a la realización de un trabajo constructivo que buscaba mostrar el proceso por medio del cual se adelantaba la construcción de las instituciones y los modelos sociales. El principal aporte de Teoría de la Justicia es establecer los principios que edifican y articulan una sociedad bien ordenada, y formular el proceso de construcción de las sociedades bien ordenadas y justas.

Una vez realizado este trabajo de construcción se debe entrar a efectuar un estudio de la cuestión de la estabilidad en las sociedades conformadas, como un complemento a la labor de Teoría de la Justicia, siguiendo a Rawls cuando afirma que la reflexión sobre la estabilidad "corrige la visión de Teoría de la Justicia, que no consigue dar cabida a la condición del pluralismo a la que conducen sus propios principios" (Rawls, 2002b : 249). Para el autor es claro que en dicha obra se plantea un pluralismo social que puede resultar problemático con posterioridad al proceso de formación de las instituciones sociales, pues introduce una serie de problemas que no son abordados totalmente en Teoría de la Justicia, lo que hace necesaria una reflexión acerca de la estabilidad social.

Aquí se busca determinar las posibilidades de permanencia y reproducción que tienen los sistemas que surgen acordes con el modelo y procedimiento de la 
Teoría de la Justicia, lo que en gran medida depende, de la forma como puedan dar respuesta a los retos presentados por el pluralismo razonable, que genera una serie de tensiones en el interior del núcleo social, debido al choque entre las diversas visiones comprensivas. La pregunta que orienta la indagación de Rawls es si "los que crecen en instituciones justas (tal como las definen los principios adoptados) desarrollan un sentido de la justicia suficientemente firme con respecto a esas actitudes e inclinaciones" (Rawls, 2002b : 246), con lo que se presenta un giro hacia la consideración de las psicologías particulares.

Para responder a esta pregunta, Rawls se encuentra con que en el marco del pluralismo razonable resulta necesario saber si "los principios adoptados, y la concepción a la que pertenecen, pueden atraerse el apoyo de la diversidad de doctrinas comprensivas razonables que forzosamente existirán en una sociedad democrática bien ordenada" (Rawls, 2002b : 246). Es decir, aceptan la proliferación de toda una serie de visiones omnicomprensivas en el escenario social se debe buscar la forma de que la sociedad se convierta en un trasfondo en donde estas puedan interactuar con mínimas garantías para que dichos grupos expresen sus opiniones y conceptos. Todo esto porque en la sociedad existen una serie de fuerzas que buscan favorecer determinados intereses particulares a costa de una amplia gama de intereses, por lo que lo primero que garantiza la estabilidad de la sociedad es evitar que los individuos sucumban ante estas tensiones.

Para completar su concepción sobre la estabilidad, Rawls considera que esta tiene una amplia conexión con la justicia como equidad entendida como una concepción política teniendo que cumplir con dos características; en primer lugar debe ser realizable, y después debe ser capaz de dar razones para mostrar por qué es práctica. En esta reflexión sobre la estabilidad está señalado el camino hacia las figuras del consenso entrecruzado y la razón pública que aparecen en Liberalismo político, y para concluir Rawls sostiene que "una concepción liberal de legitimidad política aspira a una base pública de justificación, apela a la libre razón pública y, por lo tanto, a ciudadanos que son concebidos como razonables y racionales" (Rawls, 2002b : 248).

El logro de la estabilidad en la sociedad depende directamente del consenso entrecruzado, puesto que con este último se consigue ampliar la cobertura del pacto social. En este orden de ideas, figuras como la desobediencia civil, que buscaban proteger a las minorías de la exclusión a las que podían someterlas las mayorías, pierde su razón de ser, y toda su importancia práctica dentro del modelo, por lo que desaparece en la obra Liberalismo político.

\section{Conclusión}

$\mathrm{Al}$ inicio de este escrito quisimos realizar un repaso de la Teoría de la Justicia de John Rawls con el fin de explicitar los constructos que, a nuestro modo de ver, inspiran el liberalismo racional que en una primera versión determinan el 
modelo. Así como explicar en qué sentido las figuras de la desobediencia civil y del equilibrio reflexivo constituyen desde entonces un tránsito al énfasis en la razonabilidad que se asumirá con más fuerza posteriormente, en particular desde las Conferencias Tanner sobre constructivismo kantiano en teoría moral,donde Rawls hace evidente su giro hacia el comunitarismo.

En este escrito, en efecto, Rawls asume las críticas del comunitarismo y trata de darles solución a través de la categoría de persona moral que le permite cambiar la noción excesivamente racional de agente de la primera versión, caracterizando a aquella por dos facultades: su concepción de bien y su sentido de justicia, con lo cual la posición original quedaba constituida, en lo fundamental, por comunidades a su interior. Aquí, además, expresamente Rawls ya establece lo que denominará la "prioridad de lo razonable sobre lo racional" que caracterizará a partir de entonces el énfasis de su perspectiva filosófico-política.

En el siguiente apartado se abordaron las tradiciones republicana y hegeliana con el objetivo, primero, de definir las diferentes tendencias en el interior del republicanismo. En ese orden, se precisaron dos propensiones en la tradición republicana: una que podríamos denominar neo-republicanismo de origen y evolución anglosajona, representada por autores como Pocock y Skinner, y otra, post-republicanismo, que se desarrolla en Francia y que tiene como representantes a autores como Ferry, Renaut y Messure, entre otros. Enseguida se contextualizaron las principales categorías de la filosofía hegeliana, así como el significado sustancial de su Filosofía del Derecho, con el fin de precisar las fuentes que serán claves en la comprensión del Rawls tardío.

En la tercera parte, finalmente, se exploró la recepción que tanto el republicanismo y el hegelianismo tienen en el último Rawls y los cambios que este realiza en su obra tardía. Se abordaron aquí las últimas lecciones de filosofía moral que Rawls dicta en Harvard y que versaron sobre la filosofía del derecho de Hegel de la cual retoma ideas como eticidad y reconciliación, clave en su desarrollo posterior, particularmente en el rol determinante que la categoría de conflicto juega en sus obras posteriores. En especial en la justificación que el conflicto proporciona a la figura del consenso constitucional pero también al papel que la filosofía política debe desempeñar para superarlo y, articulado con aquel, el logro de la reconciliación entre los actores del conflicto entre sí y de estos con las instituciones en procura de la misma. La ascendencia del hegelianismo es contundente en todo este planteamiento.

Pero también se rastrearon los cambios hechos por Rawls en Liberalismo Político, destacando aquí la propuesta de un consenso entrecruzado donde claramente queda en evidencia la recepción del republicanismo anglosajón. En efecto, el momento intermedio entre el consenso constitucional y el consenso entrecruzado que Rawls define como el de las virtudes cívicas sin duda integran la influencia del republicanismo, al menos del anglosajón, menos radical que 
el francés. La razonabilidad republicana se evidencia aquí en toda su magnitud dado que las virtudes juegan el papel de ambientar el clima de deliberación institucional donde las diferentes visiones onmicomprehensivas pueden proyectar y concretar su ideal de sociedad.

Finalmente se repasaron las formulaciones posteriores de Una revisión de la idea de razón pública, que termina siendo su último texto, así como de Justicia como Equidad: una Reformulación, donde la influencia del hegelianismo se hace inobjetable. La reelaboración de "La idea de razón pública" de Liberalismo Político que acomete Rawls en la primera adquiere en momentos un tinte marcadamente hegeliano que recuerda el talante de la Filosofía del Derecho de Hegel, en especial cuando Rawls explora dimensiones tan puntuales de la vida cotidiana como las de la religión y la familia en su propósito de exponer las raíces más profundas de la razón pública. Y en la segunda, el rol del reconocimiento del conflicto y la reconciliación que frente al mismo debe proponer la filosofía política consagran la potestad hegeliana en el último Rawls.

A partir de esto, la hipótesis de trabajo que este escrito buscó ilustrar creemos que fue lograda plenamente a lo largo del texto, a saber:

A partir de los ochenta Rawls introduce una serie de reformulaciones en su planteamiento inicial, subsumiendo, de una parte, las críticas comunitaristas y, de otra, incorporando a su corpus conceptual la influencia tardía tanto de la tradición republicana como de la filosofía hegeliana, siendo uno de los puntos neurálgicos de este replanteamiento la distancia que toma del modelo racional teórico de Teoría de la Justicia y el acento que empieza a colocar en los términos de razonabilidad práctica en Liberalismo Político, gracias a las categorías de overlapping consensus y razón pública que, en últimas, le permiten concretar un modelo de democracia deliberativa enraizado tanto en el republicanismo político anglosajón como en la filosofía del derecho de Hegel.

\section{Referencias}

Agra, M. J. (2004). "Ética neo-contractual", Concepciones de ética (Varios). Madrid: Trota.

Berlin, I. (1999). Four enssays on Liberty. Oxford: Oxford University Press.

Bonete Perales, E. (1990). "Génesis de la noción de persona moral", Éticas contemporáneas. Madrid: Tecnos.

Buchanan, J. (1975). The limits of liberty. Chicago: University of Chicago Press. 
Camps, V. (1997). "El segundo Rawls", Revista de Filosofía, No. 15.

Da Silveira, P. y Norman, W. (1996). "Rawlsianismo metodológico. Una introducción a la metodología dominante en la filosofía política anglosajona conpemporánea", Revista Internacional de Filosofía Política, No. 5.

De Tocqueville, A. (1998). La democracia en América. Madrid: Alianza Editorial.

Dworkin, R. (1993). Ética privada e igualitarismo político. Barcelona: Paidós.

Estévez, J. A. (1994). La constitución como proceso y la desobediencia civil. Madrid: Trotta.

Ferrara, A. (1994). "Sobre el concepto de comunidad liberal", Revista de Filosofía Política, No. 3.

Findlay, J. N. (1969). "El método dialéctico", Reexamen de Hegel, Barcelona: Grijalbo.

Ferry, L. y Renaut, A. (1984). Philosophie politique. Vol. 3, Paris: PUF.

Gargarella, R. (1999). Las teorías de la justicia después de Rawls. Barcelona: Paidós.

Gauther, D. (1994). La moral por acuerdo. Barcelona: Gedisa.

Goldman, L. (1978). Las ciencias humanas y la filosofía. Buenos Aires: Nueva Visión.

Hayek, F. (1995) [1973]. Droit, legistation et liberté. París: PUF.

Hegel, G. W. F. (1978). Escritos de juventud. México: F.C.E.

(1977). Enciclopedia de las ciencias filosóficas. México: Porrua.

(1974). "Lecciones sobre la filosofía de la historia universal",

Revista de Occidente, No. 43, pp. 43-150.

(1968a). Ciencia de la lógica. Buenos Aires: Solar.

(1968b). Filosofía del derecho. Buenos Aires: Claridad.

(1966). Fenomenología del espíritu. México: F.C.E.

Herman, B. (2001). "Prólogo", en: Rawls, J. Lecciones sobre la historia de la filosofía moral. Barcelona: Paidós.

Höffe. O. (1988). "Dans quelle mesure la theorie de John Rawls estelle kantienne", Individu et Justice Sociale. París: Seuil.

Kaufman, W. (1969). La dialéctica, en: Findlay, J. N., Reexamen de Hegel. Barcelona: Grijalbo. 
Kern, L. y Muller, H. P. (1992). La justicia idiscurso o mercado? Barcelona: Gedisa.

Konstantinov, F. V. (1965). "Ley de la negación de la negación”, Fundamentos de la teoría marxista. México: Grijalbo.

Kymilicka, W. (1995). Multicultural citizenship. Oxfor: Oxford University Press. Lefevre, H. (1976). "El dossier Hegel”, Hegel, Marx y Nietzsche. México: Siglo XXI.

Lukacs, G. (1978). "La alienación como concepto filosófico central de la fenomenología del espíritu”, El joven Hegel. Barcelona: Grijalbo.

(1975a). "El prólogo autrocrítico de 1967", Historia y conciencia de clase. Barcelona: Grijalbo.

(1975b). “¿Qué es el marxismo ortodoxo?”, Historia y conciencia de clase. Barcelona: Grijalbo.

MacIntyre, A. (1981). After y virtue. London: Duckworth.

Malen, J. (1988). Concepto y justificación de la desobediencia cívil. Barcelona: Ariel.

Marcuse, H. (1976). "Hacia el sistema de filosofía", Razón y revolución. Madrid: Alianza Editorial.

Martínez, J. (1992). "Constructivismo radical: la invención jurídica de los hechos", La imgainación jurídica. Madrid: Debate.

Mejía, O. (1997). Justicia y democracia consensual. Bogotá: Siglo del Hombre. (2000). La problemática iusfilosófica de la obediencia al derecho y la justificación constitucional de la desobediencia civil. Bogotá: Unibiblos.

Mesure, S. y Renaut, A. (2000). "La discusión républicaine du libéralisme moderme", Historie de la philosophie politique, Paris: Calman-Levy.

Mulhall, S. y Swift, A. (1992). Liberals and communitarians. Oxford/Cambridge: Blackwell.

Nino, C. (1989). "El constructivismo epistemológico: entre Rawls y Habermas", El constructivismo ético. Madrid: Centro de Estudios Internacionales.

Nozick, R. (1988). Anarquia, Estado y Utopía. México: F.C.E.

Palmier, J. M. (1977). "La filosofía del derecho”, Hegel. México: F.C.E.

Patten, R. (1996). "The republican critique of liberalism", British Journal of Politica Science, Vol. 26. 
Petit, P. (2000). Republicanismo. Una teoría sobre la libertad y el gobierno. Barcelona: Paidós.

Pocock, J.G.A. (1975). The machiavellian moment. Princenton: Princenton University.

Rawls, J. (2002). "Cuatro papeles que cumple la filosofía política”, Justicia como equidad: una reformulación. Barcelona: Paidós.

Paidós.

(2002b). La cuestión de la estabilidad, Justicia como equidad. Barcelona:

(2001a). "La filosofía como reconciliación", Lecciones sobre la historia de la filosofía moral. Barcelona: Paidós.

(2001a). Lecciones sobre la filosofía de la moral. Barcelona: Paidós.

(2001b). "Una revisión de la idea de razón pública", El derecho de gentes. Barcelona: Paidós.

(1999). Collected Papers. MA: Harverd University Press.

(1998). Teoría de la justicia. México: F.C.E.

(1993). Political liberalism. New York: Columbia University Press.

(1986). El constructivismo kantiano en la teoría moral. México: F.C.E.

Rubio, J. (1992). "El constructivismo kantiano de J. Rawls", Ética constructivista y autonomía personal. Madrid: Tecnos.

Rubio, J. (1990). "La interpretación kantiana de John Rawls", Paradigmas de la política. Barcelona: Anthropos.

Sandel, M. (1982). Liberalism and the limits of justice. Cambridge: Cambridge University Press.

Schmidt, J. (1992). "La original position y el equilibrio reflexivo", en: Kern, L. y Muller, H. P., La justicia idiscurso o mercado? Barcelona: Gedisa.

Serrau, R. (1972). Hegel y el hegelianismo. Buenos Aires: Eudeba.

Skinner, Q. (1992). "Abont justice, the common good and the priority of liberty", en: Chantal, M. (comp.) Dimensions of radical democracy. London: Verso.

Press. (1998). Liberty before liberalism. Cambridge: Cambridge University

(1992). "The italian city republics", en: Dunn, J. (comp.) Democracy: the unfinished journey. Oxford: Oxford University Press. 
Taylor, C. (1994). La ética de la autenticidad. Barcelona: Paidós. (1989). Sources of the self. Cambridge, M.A.: Harvard University Press.

Thiebant, C. (1994). "Universidad, pluralismo cultural e identidad moral", Revista de Filosofía Política, No. 3.

Walzer, M. (1983). Spheres of justice. New York: Basic Books. 